\title{
AGNIESZKA IWANICKA
}

Uniwersytet im. Adama Mickiewicza w Poznaniu

\section{Od biernego odbiorcy do aktywnego mediakreatora - małe dzieci i TIK w świetle badań własnych}

\begin{abstract}
Agnieszka Iwanicka, Od biernego odbiorcy do aktywnego mediakreatora małe dzieci $i$ TIK $w$ świetle badań własnych [From passive recipients to active mediacreators: small children and ICT in the light of own studies]. Interdyscyplinarne Konteksty Pedagogiki Specjalnej, nr 23, Poznań 2018. Pp. 143-160. Adam Mickiewicz University Press. ISSN 2300-391X. DOI: https:/ / doi.org/10.14746/ikps.2018.23.08

Small children show a lot of media activity: they are perfectly capable of handling new technologies, they have been using them since the first years of their life. What activities they show depends on the family home and the behaviors they observe with their parents. With their support and providing positive patterns, the child can become not only a passive media user, but also an active media content creator, a kind of mediacreator, which over time will have a real impact on the reality in which he grows up. In the article, I present some of the results of the my research, in which I checked what role the media plays in the life of a child in an early school age. I try to answer the question, what media activities are displayed by children whether it is only passive and imitative, or maybe they are actively creating media content.
\end{abstract}

KEY WORDS: ICT, media, media literacy, coding, media content creator, children in early school age 


\section{Wstęp}

Mediatyzacja współczesnego świata stała się faktem, przynosząc wiele nowego nie tylko w sferze komunikacyjnej (np. zmiana rodzaju i jakości interakcji międzyludzkich), informacyjnej czy edukacyjnej, ale i w sferze kształtowania naszych codziennych aktywności. To, które z nich są naszym udziałem, zależy od ich poziomu atrakcyjności dla nas, stopnia zaspokojenia potrzeb $\mathrm{w}$ świecie offline oraz oddziaływania najbliższego otoczenia. Nieco inaczej sytuacja wygląda, gdy mówimy o małych dzieciach i podejmowanych przez nie aktywnościach - tutaj na znaczeniu zyskuje środowisko rodzinne i wzorce osobowe dostarczane przez rodziców i inne osoby dorosłe (np. dziadków) z najbliższego otoczenia. Właśnie od nich dziecko uczy się używania mediów i to oni są odpowiedzialni za to, jak wcześnie i w jaki sposób będzie korzystało z technologii informacyjno-komunikacyjnych (TIK). To rodzice $\mathrm{w}$ początkowym okresie życia dziecka (a w kolejnych latach także szkoła i nauczyciele) ponoszą odpowiedzialność za szeroko rozumianą edukację medialną potomstwa, a to, w jaki sposób sami korzystają z mediów, znajduje odzwierciedlenie $\mathrm{w}$ kompetencjach medialnych ich dzieci oraz podejmowanych przez nie medialnych aktywnościach 1 . Wysokie kompetencje medialne rodziców z reguły przekładają się na takie same kompetencje ich podopiecznych - poprzez swoje zachowania nie tylko inicjują, ale i ułatwiają dzieciom naukę prawidłowego korzystania z TIK, dając im pozytywny przykład².

Małe dziecko nie jest $\mathrm{w}$ stanie samo poradzić sobie $\mathrm{z}$ odbiorem komunikatów medialnych - potrzebuje wsparcia dorosłych $\mathrm{w}$ dążeniu do tego, aby stać się ich świadomym, krytycznym odbiorcą, aby media były dla niego użytecznym narzędziem, które będzie

${ }^{1} \mathrm{~J}$. Juszczyk-Rygałło, Wczesnoszkolna edukacja medialna jako wprowadzenie do edukacji całożyciowej, Prace Naukowe Akademii im. Jana Długosza w Częstochowie, Pedagogika 2015, t. XXIV, Akademia im. Jana Długosza w Częstochowie, Częstochowa 2015, s. 90.

2 J. Marsch i in., Digital Begginings: Young children's use of popular culture, media and new technology, Sheffield 2015, s. 12. 
wykorzystywało zgodnie z założonymi przez siebie celami. Tylko w efekcie takich działań stanie się aktywnym mediakreatorem twórcą medialnych treści, a nie tylko biernym konsumentem komunikatów dostarczanych mu przez innych użytkowników nowych technologii. Człowiek aktywny medialnie ma szereg kompetencji, które pozwalają mu w pełni uczestniczyć w cyfrowej rzeczywistości: świadomie korzysta z mediów; potrafi dokonać ich krytycznej oceny; zna mechanizmy oddziaływania mediów; dobiera wartościowe dla siebie komunikaty; weryfikuje ich pochodzenie; samodzielnie tworzy materiały, które następnie bądź umieszcza np. w sieci do wspólnego użytku, bądź wykorzystuje do własnych potrzeb (np. pracy, zabawy); zna i potrafi użyć dostępne narzędzia potrzebne do wykonania danej aktywności; potrafi pracować w grupie, używając nowych technologii. Współcześnie to właśnie osoba aktywnie wykorzysująca media w szeroko rozumianym procesie tworzenia (nadawca treści medialnych - mediakreator) jest postrzegana jako ta najbardziej kompetentna medialnie i poszukiwana na rynku pracy.

Aktywność medialna dzieci we wczesnym wieku szkolnym wydała mi się na tyle interesująca, że postanowiłam sprawdzić, czy występuje już w tym okresie życia dzieci oraz jaki - w opiniach rodziców - ma ona charakter $\mathrm{w}$ pozaszkolnym czasie dziecka, w jego najbliższym, rodzinnym środowisku. Poniżej przedstawiam najważniejsze wyniki z przeprowadzonego badania.

\section{Relacja media - dziecko}

Wczesne dzieciństwo coraz bardziej związane jest z nowymi mediami - na popularności zyskują zwłaszcza media ekranowe, $\mathrm{w}$ tym smartfon, tablet $\mathrm{i}$ komputer $\mathrm{z}$ dostępem do internetu ${ }^{3}$. Według najnowszych raportów dzieci są jednymi z najczęstszych użytkowników internetu. Unicef podaje, że jeden na trzech użytkowni-

${ }^{3}$ J. Juszczyk-Rygałło, op. cit., s. 94. 
ków internetu to dziecko4, przy czym wiek inicjacji medialnej znacząco się obniża. Według Dominika Batorskiego aż 21\% dzieci korzysta z internetu już w wieku 3 lat, w wieku 4 lat odsetek wzrasta do $25 \%$, wśród pierwszoklasistów rośnie do niemal $70 \%$. Zdecydowana większość dzieci, rozpoczynając naukę w szkole, jest już dobrze zaznajomiona $\mathrm{z}$ nowymi technologiami - będąc bystrymi obserwatorami, dorastają, patrząc, jak z mediów korzystają ich rodzice i rodzeństwo ${ }^{5}$. Zasadne wydaje się więc zastanowienie, jakimi aktywnościami medialnymi wykazują się dzieci w wieku wczesnoszkolnym? Z jakich mediów korzystają w swoim czasie wolnym i jaka jest jakość tego kontaktu? Czy jest on tylko bierny i odtwórczy, czy może dzieci są też twórcami treści medialnych? Pytania te wydały mi się na tyle ważne, że przedmiotem moich badań uczyniłam obecność mediów w życiu dziecka we wczesnym wieku szkolnym. Szczególnie interesujące wydało mi się sprawdzenie rodzaju i zakresu podejmowanych przez dzieci medialnych aktywności.

Przeprowadzone przeze mnie badania - których wyniki są jedynie częściowo zaprezentowane w poniższym opracowaniu - miały charakter diagnostyczny i były badaniami pilotażowymi. Ich celem była standaryzacja założonej procedury badawczej, w tym narzędzia badawczego i zmierzały do ustalenia danego stanu rzeczy, bez zamiaru głębokiego wnikania $\mathrm{w}$ istniejące między nimi zależności sprawcze $^{6}$. W badaniu zastosowałam sondaż diagnostyczny i posłużyłam się techniką ankiety online. Kwestionariusz zawierał 30 pytań, które miały formę zamkniętą $\mathrm{z}$ kategoriami do wyboru, skalą, rangami oraz elementami otwartymi. Osoby biorące udział $\mathrm{w}$ badaniu były rodzicami dzieci w wieku wczesnoszkolnym (klasy I-III szkoły podstawowej). W sondażu wzięły udział 192 osoby,

4 Unicef, The State of the World's Children 2017: Children in a Digital World, https://www.unicef.org/publications/index_101992.html [dostęp: 9.06.2018].

${ }^{5}$ D. Batorski, Technologie i media w domach i życiu Polaków, [w:] Diagnoza społeczna 2015: Warunki i jakość życia Polaków, red. J. Czapiński, T. Panek, Rada Monitoringu Społecznego, Warszawa 2015, s. 373-395.

${ }^{6} \mathrm{M}$. Łobocki, Wprowadzenie do metodologii badań pedagogicznych, Oficyna Wydawnicza „Impuls”, Kraków 2004, s. 67. 
w tym aż 185 kobiet i tylko 7 mężczyzn, większość z nich była mieszkańcami dużego miasta $(75 \%)$, powyżej 30. roku życia $(70 \%)$ i miała dwoje lub więcej dzieci (69\%). We wszystkich domach badanych osób był przynajmniej jeden telewizor z dostępem do telewizji satelitarnej i komputer z dostępem do internetu (aż 40\% gospodarstw domowych posiadało dwa lub więcej komputery). Wszystkie badane osoby miały telefon z dostępem do internetu, aż $60 \%$ rodziców zadeklarowało, że swój własny smartfon ma także ich dziecko. Taki dostęp do nowych technologii przekłada się na umiejętności medialne dzieci - jak pokazują badania, ponad jedna trzecia dzieci przed ukończeniem pierwszego roku życia potrafi korzystać już z ekranów dotykowych, smartfonów lub tabletów ${ }^{7}$. Inicjacja medialna dzieci z roku na roku się obniża - jeszcze $\mathrm{w}$ roku 2011 odsetek rocznych dzieci korzystających z mediów wynosił zaledwie $10 \%$. Podobnie skala diagnozowane zjawiska rośnie w innych przedziałach wiekowych, by u dzieci w wieku 5-8 lat osiągnać próg aż $83 \%$ użytkowników mediów ${ }^{8}$. Niewątpliwie za taki stan rzeczy odpowiedzialna jest ogólna dostępność nowych technologii informacyjno-komunikacyjnych, znaczne obniżenie ich kosztów produkcji i zakupu oraz wypieranie tradycyjnych mediów (tzw. starych, analogowych) przez multimedia, zwane nowymi mediami. Status materialny rodzin jest $\mathrm{w}$ dużej mierze odpowiedzialny za dostępność do mediów, nie jest ona jednak równoznaczna z ich intensywnym wykorzystaniem - im wyższe wykształcenie rodzi-

7 Por. H. Kabali i in. First Exposure and Use of Mobile Media in Young Children, Pediatric Academic Societies' Annual Meeting, 25-28.04.2015, San Diego, Abstrakt: http://www.abstracts2view.com/pas/view.php?nu=PAS15L1_1165.3; 2015; C. Kemp, Babies as young as 6 months using mobile media: Survey shows most 2-year-olds using mobile devices, with some spending more than an hour a day on screens, AAP News, https://www. aap.org/en-us/about-the-aap/aap-press-room/pages/Babies-as-Young-as-6-MonthsUsing-Mobile-Media.aspx, [dostęp: 10.08.2018].

8 Por. A Common Sense Media Research Study, Zero to eight. Children's Media Use in America in 2011, 2013, https://www.commonsensemedia.org/research/ze ro-to-eight-childrens-media-use-in-america-2013 [dostęp: 10.08.2018]; D. Batorski, op. cit., s. 373-395. 
ców i ich medialna świadomość, tym rozważniejsze korzystanie z mediów w takiej rodzinie ${ }^{9}$.

Aż 95\% dzieci jeszcze przed rozpoczęciem nauki w szkole podstawowej ma intensywny kontakt $\mathrm{z}$ mediami, a odsetek ten stale rośnie $^{10}$. Z przeprowadzonych przeze mnie badań wynika, że wszystkie dzieci - niezależnie od wykształcenia rodziców i miejsca zamieszkania - miały codzienny kontakt z mediami: telewizorem (90\% badanych), tabletem (40\%), komputerem z dostępem do internetu (60\%) czy telefonem komórkowym (69\%) - własnym bądź rodziców. Częstotliwość posiadania i użytkowania telefonu komórkowego - smartfonu - rośnie wraz z wiekiem dziecka - jego wyraźny

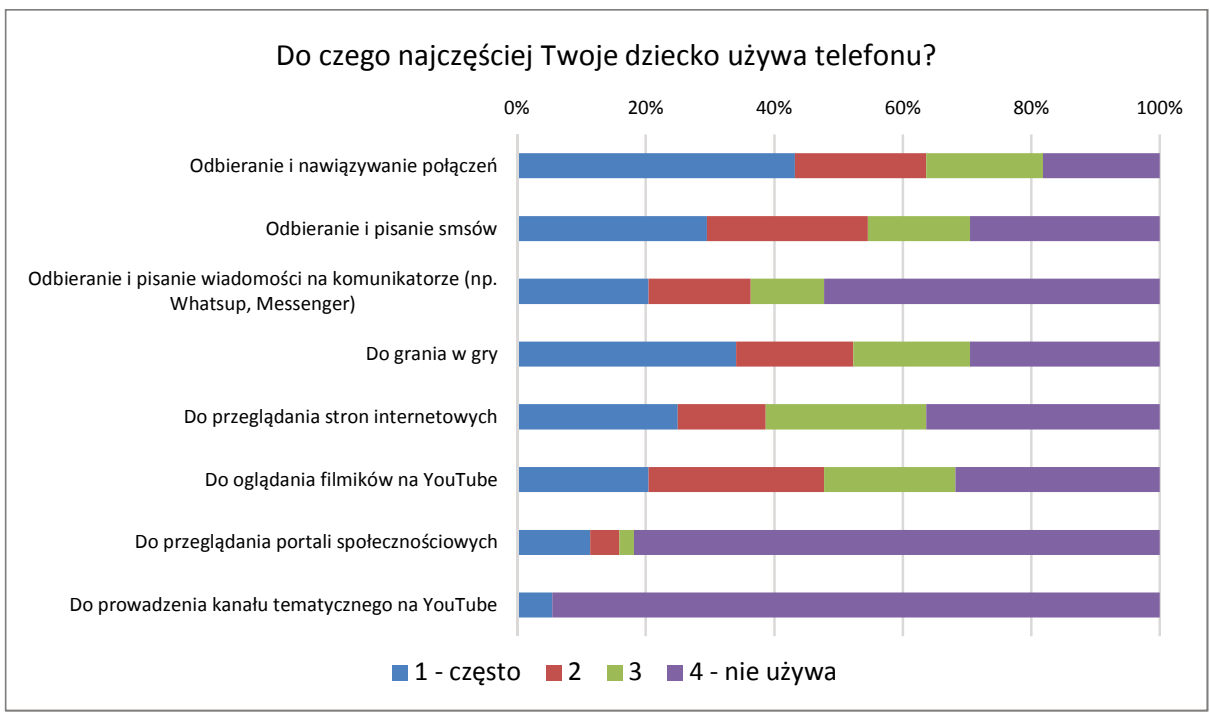

Wykres 1. Używanie smartfonu przez dzieci

Źródło: wyniki badań własnych

${ }^{9}$ D. Batorski, Dzieci z sieci - dostęp i korzystanie z internetu przez dzieci w wieku przedszkolnym, [w:] Małe dzieci w świecie technologii informacyjno-komunikacyjnych. Pomiędzy utopijnymi szansami a przesadzonymi zagrożeniami, red. J. Pyżalski, Wydawnictwo „Eter”, Łódź 2017, s. 87.

10 D. Batorski, Technologie i media ..., s. 373-395. 
wzrost można odnotować w trzeciej klasie, po przystąpieniu dziecka do Pierwszej Komunii Świętej11. Dzieci używają ich najczęściej do odbierania i nawiązywania połączeń, grania w gry i przeglądania stron internetowych, tylko niewielki odsetek dzieci na telefonie przegląda portale społecznościowe bądź wykonuje inne aktywne czynności np. prowadzi swój własny kanał tematyczny na YouTube.

Jeśli dziecko ma telefon, to często ma na nim zainstalowane popularne aplikacje: Snapchat, Instagram czy Musical.ly (obecnie TikTok). Cieszy fakt, że tylko niewielki procent dzieci ma konto na Facebooku, który formalnie dozwolony jest dla dzieci od 13. roku życia. Może to świadczyć o coraz wyższej świadomości medialnej rodziców, którzy nie zgadzają się, aby ich dziecko korzystało z tego

Czy Twoje dziecko ma zainstalowaną na telefonie którąś z wymienionych aplikacji?

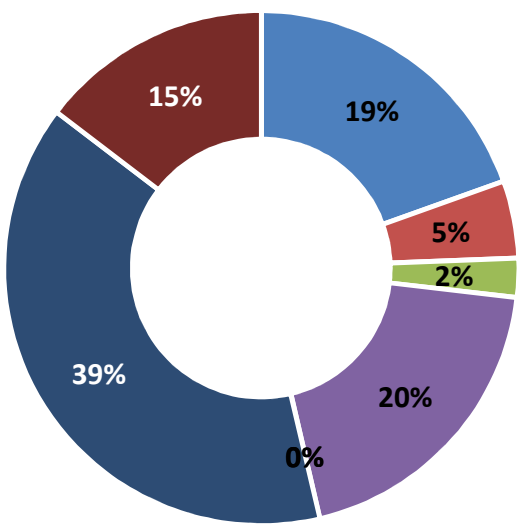

- Snapchat

- Instagram

- Facebook

- Musical.ly

- Inne

- Nie ma żadnej z tych aplikacji

Wykres 2. Aplikacje na telefonie dziecka

Źródło: wyniki badań własnych

11 D. Batorski, Dzieci z sieci-dostęp i..., s. 80. 
popularnego portalu społecznościowego zbyt wcześnie. Rosnącą świadomość dorosłych możemy odnotować też w zakresie czasu, jaki dziecko poświęca mediom. Aż $60 \%$ rodziców deklaruje, że kontrolują, ile czasu ich dziecko używa poszczególnych mediów. Jednak $19 \%$ przyznaje, że nie zwraca na to uwagi bądź zgadza się na naginanie ustalonych zasad i ulega dziecku, przedłużając wyznaczone czas korzystania z mediów (21\%).

Pośród dzieci korzystających z popularnej aplikacji Musical.ly aż 65\% aktywnie tworzy na niej własne teledyski, którymi dzieli się z innymi użytkownikami. Pozostali są biernymi obserwatorami serwisu. Podobnie aplikacje Snapchat i Instagram - są chętnie używane przez dzieci do robienia zdjęć (80\%), kręcenia krótkich filmików (45\%) czy nagrywanie tzw. Instastory (20\%), które następnie są umieszczane $\mathrm{w}$ serwisach i oceniane bądź komentowane przez innych internautów. Nie są to jednak wytwory podejmujące szczególnie wartościową tematykę - najczęściej obrazują codzienne życie dzieci, podejmowane przez nie aktywności, hobby i zainteresowania, pokazują ich najbliższe otoczenie, ulubione przedmioty, zwierzęta, relacje z obejrzanych filmów czy odsłuchanych piosenek. Młodzi ludzie jednak chętnie używają tych aplikacji, nie tylko nagrywając własne materiały, ale i oglądając treści udostępniane przez innych użytkowników.

Jeszcze do niedawna popularna telewizja, coraz bardziej traci na atrakcyjności, stając się medium towarzyszącym (tak jak dawniej radio) wykonywaniu innych czynności przez dziecko. Wynika to być może z jej braku interaktywności - to medium o typowo biernym charakterze odbioru, które staje się mało atrakcyjne dla dzieci przyzwyczajonych do responsywnych mediów. Według deklaracji rodziców aż 60\% dzieci, oglądając telewizję (najczęściej są to bajki lub filmy animowane), równocześnie wykonuje inne czynności: bawi się zabawkami tradycyjnymi (35\%), przegląda coś na telefonie (10\%), wykonuje jakieś czynności na komputerze $(6 \%)$, przygotowuje się do zajęć szkolnych (4\%) lub je posiłek (5\%). Coraz popularniejszym medium wśród dzieci staje się tablet - odsetek korzystających z niego dzieci rośnie z roku na rok, jest ich więcej niż 
dzieci używających komputera $\mathrm{z}$ dostępem do internetu' ${ }^{12}$. O jego atrakcyjności decyduje przede wszystkim łatwa, niemal intuicyjna obsługa, często dostosowany do wieku dziecka interfejs, wysoka mobilność urządzenia (można je łatwo przenieść w inne, wygodne dla dziecka miejsce, bez konieczności podłączania kabla zasilającego) i względne bezpieczeństwo obsługi - istnieje dużo mniejsze prawdopodobieństwo, że korzystając z tabletu, dziecko spotka się $\mathrm{z}$ niepożądanymi treściami, najczęściej są bowiem na nim zainstalowane tylko sprawdzone przez rodziców aplikacje, bajki i filmy. Jego cechą jest też interaktywność, która jest ważną własnością multimediów: dzieci wiedzą, że na pewne treści medialne mogą od razu

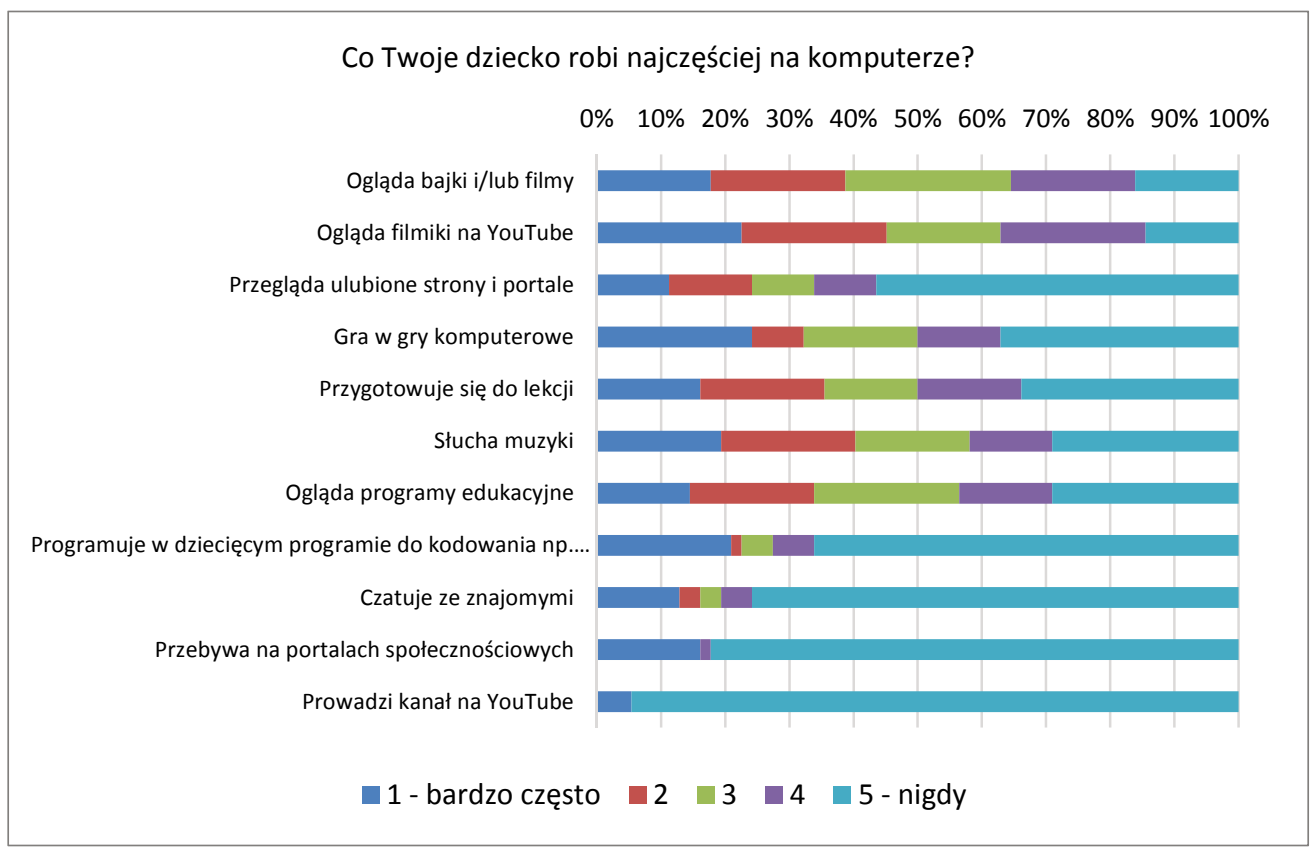

Wykres 3. Czynności wykonywane przez dzieci na komputerze

Źródło: wyniki badań własnych

${ }^{12}$ D. Batorski, Technologie i media..., s. 373-395. 
reagować, realnie wpływać na ich kształt, a nawet kreować nowe treści. To właśnie tablet, komputer i smartfon są dla nich najbardziej interaktywnymi mediami, równocześnie zyskując status najatrakcyjniejszych.

Pytani o czynności wykonywane przez dzieci na komputerze, rodzice wskazują kolejno: granie w gry komputerowe i oglądanie filmików na YouTube. Dalej wskazują programowanie, słuchanie muzyki i oglądanie bajek i filmów.

Warto dodać, że cechami wyróżniającymi najmłodsze pokolenia stają się: potrzeba dużej interaktywności medialnego środowiska, umiejętność i chęć współtworzenia treści umieszczanych następnie w sieci oraz poczucie wspólnoty z wirtualną społecznością, która nabiera dla nich cech realnych wspólnot.

\section{Dziecko jako kreator treści medialnych}

W projekcie EU Kids Online ${ }^{13}$ wytypowano trzy rodzaju ról, które może przyjąć młody człowiek korzystający z nowych technologii. Może być odbiorcą treści, uczestnikiem (gdy kontaktuje się z innymi internautami online) lub aktorem - gdy samodzielnie, z własnej inicjatywy podejmuje pewne aktywności przy udziale internetu. Jako odbiorca treści medialnych nie wykazuje się żadnymi aktywnościami poza biernym korzystaniem z dostępnym zasobów medialnych, dopasowanych (z założenia) do jego możliwości poznawczych. Będąc uczestnikiem, wykorzystuje w pełni interaktywność mediów do komunikowania się z innymi członkami grup, do których przynależy (rodzina, grupa rówieśnicza, grupy zainteresowań), w zależności od wieku i umiejętności bądź to przy pomocy osób dorosłych, bądź samodzielnie, przy udziale komunikatorów i mediów społecznościowych. Takie uczestnictwo pozwala nie tylko

13 S. Livingstone, L. Haddon, Eu Kids Online: Final report, London 2009, s. 10 http://www.lse.ac.uk/media@lse/research/EUKidsOnline/EU\%20Kids\%20I\%20(20 06-9)/EU\%20Kids \%20Online\% 20I\% 20Reports/EUKidsOnlineFinalReport.pdf [dostęp: 10.08.2018]. 
na komunikowanie się, ale i wymianę różnego rodzaju informacji. Kolejna z przyjmowanych ról - aktor - pozwala na kreatywne wyrażanie samego siebie poprzez samodzielne produkowanie, wytwarzanie i wreszcie publikowanie treści medialnych, co stanowi istotę wspomnianej wcześniej idei kreacji treści ${ }^{14}$. Ta rola jest dostępna nielicznym - w moich badaniach tylko niewielki procent dzieci w tym wieku był zaangażowany w taką postawę, reszta wchodziła tylko w dwie pozostałe role. Inne badania pokazują, że nasze stereotypowe postrzeganie internetu jako miejsca, w którym dzieci i młodzież przejawiają negatywne zachowania i mają do czynienia tylko z samymi zagrożeniami, jest mylące: większość działań przez nich podejmowanych ma charakter neutralny lub pozytywny ${ }^{15}$. Jednak wśród nich tylko nieznaczna część to działania aktywne, wykraczające poza przeciętne wykorzystanie internetu. Zaliczyć do nich możemy aktywności szczególnie wartościowe nie tylko dla samej jednostki, ale i dla całego społeczeństwa, działania twórcze, rozwijające kreatywność czy wspomagające rozwój. Wiemy o nich niewiele - bowiem to zagrożenia internetu są zazwyczaj w kręgu zainteresowań badaczy, wciąż mało jest badań ujmujących holistycznie - a więc wskazujących zarówno pozytywne, jak i negatywne możliwości wykorzystania internetu przez najmłodszych, choć i zaczyna dochodzić do pozytywnych zmian ${ }^{16}$.

14 A. Lenhart, M. Madden, A.R. Macgill, Teens and Social Media, Pew Internet $\mathcal{E}$ American Life Project, 2009, http://www.pewinternet.org/2018/05/31/teens-socialmedia-technology-2018/ [dostęp: 10.08.2018].

15 D. Finkelhor, K. J. Mitchell, J. Wolak, Online victimization: A report on the nation's youth, National Center for the Missing and Exploited Children, Alexandria 2000, http://www.unh.edu/ccrc/pdf/Victimization_Online_Survey.pdf [dostęp: 11.08.2018]; E. Dunkels, G.-M. Franberg, C. Hallgren, Young people and online risks [w:] Youth Culture and Net Culture: Online Social Practices, red. E. Dunkels, G-M. Franberg, C. Hallgren, I-Global 2011, http:/ / www.mucf.se/sites/default/files/young-peopleand-online-risk.pdf [dostęp: 11.08.2018].

16 J. Pyżalski, Od paradygmatu ryzyka do paradygmatu szans: prorozwojowe i prospołeczne używanie internetu przez dzieci i młodzież, [w:] Nastolatki wobec internetu, red. M. Tanaś, NASK, Warszawa 2016, s. 57. https://akademia.nask.pl/publikacje/Na stolatki_wobec_internetu_.pdf [dostęp: 11.08.2018]. 
Dzieci korzystają z mediów głównie w celach rozrywkowych ${ }^{17}$, posługując się nimi w sposób bardzo sprawny. Nie mają problemu z samodzielną obsługą telewizora (100\% respondentów), tabletu $(88 \%)$, smartfona $(79 \%)$ czy komputera (tylko $37 \%$ potrzebuje niewielkiej pomocy rodziców do włączenia ulubionej bajki, filmu z płyty czy znalezienia strony internetowej). $\mathrm{W}$ interesującej mnie grupie wiekowej istnieje spore zróżnicowanie co do sposobu korzystania z nowych technologii - od biernego odbioru komunikatów medialnych (np. oglądania filmów i bajek) do całkiem aktywnego np. kręcenia filmików, robienia zdjęć przy pomocy aparatu w smartfonie czy programowania edukacyjnych robotów. W kontekście aktywności medialnej dziecka warto wspomnieć o aktywności twórczej i odtwórczej: zachowania naśladowcze, powtarzające się, uznawane są za niższe formy aktywności i nazywane odtwórczymi; wyższe, innowacyjne, wykraczające poza stereotypowe zachowania i w prowadzające $\mathrm{w}$ działania nowatorski element do twórczych ${ }^{18}$. Nowe technologie informacyjno-komunikacyjne prowokują dzieci do aktywnych, twórczych zachowań - szczególne miejsce zajmuje tutaj komputer i internet ${ }^{19}$ oraz edukacyjne roboty. $\mathrm{W}$ tej roli idealnie spisuje się programowanie $\mathrm{w}$ prostych, wizualnych językach, np. w Scratchu, które nie tylko uczy dzieci logicznego, algorytmicznego myślenia, ale rozwija kreatywność, wyobraźnię i aktywne, twórcze działanie. I chociaż sam program komputerowy jest wytworem cudzej aktywności i jego postawy twórczej, to może implikować takie zachowania po stronie swoich użytkowników. Roboty

${ }^{17}$ R. Zevenbergen, H. Logan, Computer use by preschool children: Rethinking practices as digital natives come to preschool, Australian Journal of Early Childchood, 2008, https://research-repository.griffith.edu.au/bitstream/handle/10072/23047/53861_ 1.pdf;jsessionid=5AECB87B4BB315B523C9AD98D3513C3F?sequence=1 [dostęp: 10.08. 2018].

${ }^{18}$ E.B. Hurlock, Rozwój dziecka, Wydawnictwo Naukowe PWN, Warszawa 1985, s. 90; M. Przetacznik-Gierowska, G. Makiełło-Jarża, Psychologia rozwojowa i wychowawcza wieku dziecięcego, Wydawnictwa Szkolne i pedagogiczne, Warszawa 1992, s. 57.

${ }^{19} \mathrm{~S}$. Papert, Burze mózgów. Dzieci i komputery, Wydawnictwo Naukowe PWN, Warszawa 1996, s.16; A. Walat, Wprowadzenie do jezyka i środowiska Logo, OEliZK, Warszawa 1996, s. 27. 
edukacyjne stają się coraz popularniejszymi narzędziami TIK - ich cena sprawia, że nie każdy może sobie na nie pozwolić, decyzję zakupu podejmuje jednak coraz więcej szkół, wykorzystując je do realizacji podstawy programowej, w której od roku znajduje się zapis o konieczności wdrażania nowych technologii - w tym umiejętności okołoprogramistycznych - do edukacji wczesnoszkolnej. Zaczynają też pojawiać się w domach $(11 \%$ badanych rodziców zadeklarowało jego posiadanie), co cieszy, są bowiem świetnym narzędziem rozwijającym kreatywność dziecka, uczącym logicznego, analitycznego myślenia, samodzielnego rozwiązywania problemów, dokładności, precyzji i sumienności. Integrują też rodzinę - tylko 8\% rodziców odpowiedziało, że ich dziecko bawi się w domu takim robotem samodzielnie, pozostałe potrzebują pomocy dorosłego, co jest świetną okazją do wspólnej zabawy i pracy.

Wprowadzona do szkół 1 września 2017 r. nowa podstawa programowa stawia przed nauczycielem m.in. takie cele, jak: rozwijanie kreatywności, umiejętności krytycznego i logicznego myślenia, rozumowania, argumentowania i wnioskowania, rozbudzanie ciekawości poznawczej uczniów oraz motywacji do nauki ${ }^{20}$. Większość zmian związana jest $\mathrm{z}$ osiągnięciami ucznia w zakresie programowania i rozwiązywania problemów z wykorzystaniem komputera i innych urządzeń cyfrowych i dotyczy takich aktywności, jak: posługiwanie się komputerem do wykonania zadania, programowanie wizualne, tworzenie komputerowych komunikatów graficznych, korzystanie z zasobów internetowych. Takie możliwości daje wspomniane już programowanie w Scratchu, który zyskuje na popularności w polskich szkołach, a także poza nimi, w środowisku domowym dziecka.

Programowanie to umiejętność, która pozwala dzieciom rozwijać myślenie kreatywne, wyciągać logiczne wnioski, doskonalić umiejętności analityczne, samodzielnie dochodzić do rozwiązań. Obok znajomości języka ojczystego i obcego uznawane jest dziś za

20 Podstawa programowa kształcenia ogólnego dla szkoły podstawowej, s. 1, http://edu kacjawczesnoszkolna.edu.pl/wpcontent/uploads/2017/02/podstawa_programowa_ 2017_sp_edukacjawczesnoszkolnaedupl.pdf [dostęp: 1.08.2018]. 


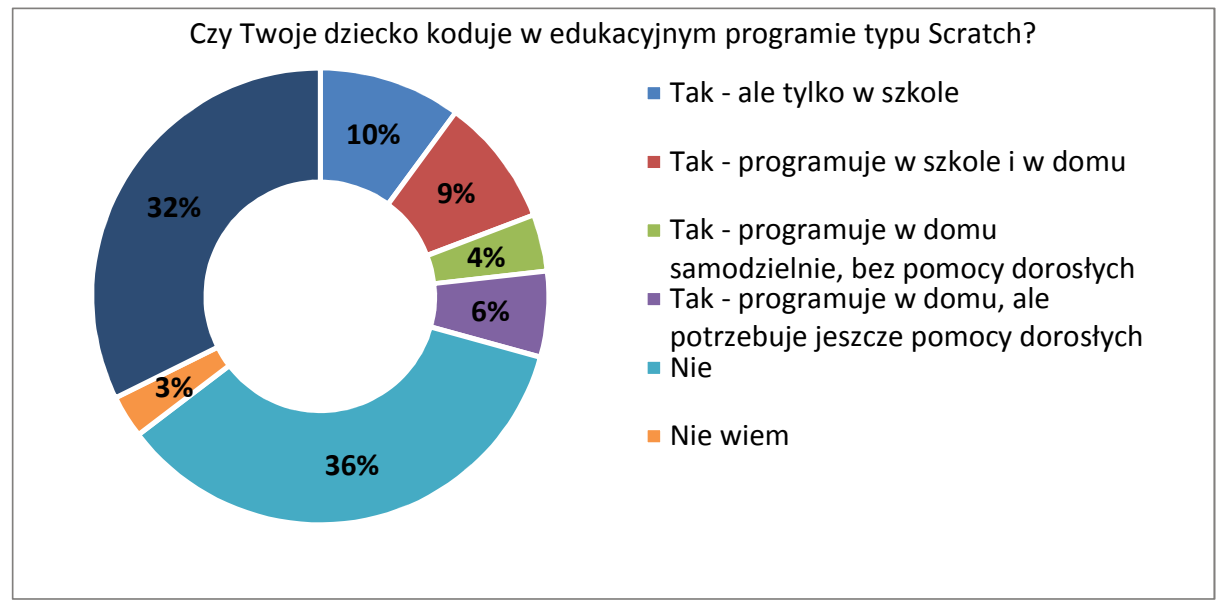

Wykres 4. Kodowanie w Scratchu przez dzieci w wieku wczesnoszkolnym Źródło: wyniki badań własnych

trzeci język, niezbędny do zrozumienia otaczającego nas świata i dynamicznie w nim zachodzących zmian komunikacyjno-informacyjnych. Jego propagowanie nie ma na celu wykształcenia rzeszy programistów - ma przede wszystkim sprawić, że dziecko, uczeń nie będzie biernym odbiorca TIK, ale będzie potrafił je ze zrozumieniem, kreatywnie wykorzystać do własnych celów i potrzeb.

W zależności od umiejętności dziecka, jego potrzeb i zainteresowań, instrumenty TIK dają możliwość różnego rodzaju zachowań doskonalących ważne kompetencje dziecka. Pozwalają zaangażować się w działania, które nie tylko są dla niego atrakcyjne, lecz także motywują i stymulują jego rozwój. Warto przywołać pojęcie edutainment i playful learning - dzięki temu, że producenci narzędzi TIK starają się opakować je w jak najatrakcyjniejszą formę, dla wielu dzieci stają się one dobrym źródłem rozrywki i zabawy, sprawiając, że przy ich pomocy się uczą ${ }^{21}$. Takimi narzędziami są chociażby

${ }^{21}$ M. Resnick, Computer as Paintbrush: Technology, Play, and the Creative Society, [w:] Play = Learning: How play motivates and enhances children's cognitive and social- 
wspomniane roboty edukacyjne, programy do nauki kodowania czy programowalne klocki typu Lego WeDo - dziecko bawiąc się nimi, przy okazji kształci ważne umiejętności. Poza wymienionymi wcześniej walorami możemy do nich zaliczyć: wyliczanie, łączenie przedmiotów w grupy, segregowanie ich, praktyczne wykorzystanie zdobytych wcześniej wiadomości poprzez łączenie ich z nowo nabytymi. Nie są jeszcze tak popularne, ale zaczynają pojawiać się polskich domach, zachęcając dzieci do kreatywnej nauki przez zabawę. Posiadanie takich klocków zadeklarowało 13\% badanych rodziców (wśród tej grupy jednak tylko 8\% dzieci korzysta $\mathrm{z}$ nich bardzo często, reszta wykorzystuje je do zabawy/nauki rzadko).

$Z$ punktu rozwoju dziecka szczególnie wartościowe są te instrumenty TIK, które nie tylko kształcą pewne narzędziowe umiejętności medialne (np. programy tutoriale do robienia zdjęć czy kręcenia filmów), ale mają potencjał wykorzystywania ich do działań edukacyjnych i twórczych ${ }^{22}$. To właśnie narzędzia, które przygotowują dzieci do roli mediakreatorów bądź tzw. kreatorów treści (ang. content creators), są szczególnie cenne z punktu widzenia rozwoju dziecka. Jak pokazują badania, osoby które wykazują się jakimiś aktywnościami w sieci, często takie wzory funkcjonowania przejawiają w środowisku offline ${ }^{23}$ (np. w szkole, grupie rówieśniczej, kółku zainteresowań itd.). Im młodsze dzieci, tym kreatywnych i aktywnych zachowań przy udziale mediów mniej, a te które są, często odbywają się przy pomocy dorosłych - pojawiające się jednak łatwe w obsłudze instrumenty TIK sprawiają, że coraz młodsze dzieci zaczynają być aktywnymi twórcami w sieci, a naszym zadaniem jest zachęcać do nich dziecko, pokazując dobre praktyki i przykłady wartościowego wykorzystania narzędzi TIK.

emotional growth, red. D. Singer, R. Golikoff, K. Hirsh-Pasek, Oxford University Press, 2006. http://www.computerclubhouse.org/sites/default/files/ComputerAs Paintbrush_Singer.pdf [dostęp: 10.08.2018].

22 M. Resnick, op. cit.

23 A. Lenhart, M. Madden, A.R. Macgill, Teens and Social Media, Pew Internet $\mathcal{E}$ American Life Project, 2009, http://www.pewinternet.org/2018/05/31/teens-socialmedia-technology-2018/ [dostęp: 10.08.2018]. 


\section{Zakończenie}

Dzięki mediom dzieci doświadczają poczucia sukcesu, obserwują swój postęp i rozwój w danej dziedzinie, czują się spełnione, kiedy mogą dzielić się z innymi swoimi wytworami, prezentować je grupie rówieśniczej i razem z nimi używać instrumentów TIK ${ }^{24}$. Współdzielenie jest istotną cechą nowych mediów: takie narzędzia jak YouTube, Instagram, Snapchat czy Musical.ly opierają swą działalność o ideę tworzenia nowych treści z jednej strony, z drugiej udostępniania ich i współdzielenia $\mathrm{z}$ innymi użytkownikami. Cecha ta jest wartością pożądaną przez dzieci w wieku wczesnoszkolnym, dla których uznanie grupy rówieśniczej ma duże znaczenie współcześnie można je zdobyć np. przez pokazywanie swoich wytworów w mediach społecznościowych. Komplementy (w postaci pozytywnych komentarzy) pojawiające się $\mathrm{w}$ grupie mają wartość dla dziecka - podkreślają jego kompetencje, są potwierdzeniem, że wysiłki wkładane $\mathrm{w}$ funkcjonowanie $\mathrm{w}$ grupie społecznej zostały zauważone. Aby je otrzymać, nie wystarczy w sieci być biernym obserwatorem - trzeba wykazać się jakąś aktywnością, konkretnym działaniem, które zostanie zauważone przez innych. Działania te przybierają różne formy w zależności od medium, w którym dziecko wykazuje się aktywnością. Na potrzeby badania wyróżniłam takie jak: robienie zdjęć smartfonem, kręcenie filmików i teledysków, prowadzenie kanału tematycznego na YouTube, kodowanie w programach wizualnych typu Scratch, programowanie edukacyjnych robotów czy klocków typu Lego WeDo. Wymienione aktywności nie są jeszcze mocno obecne w życiu dziecka w klasie I-III - są raczej dodatkiem do wykonywanych działań przy udziale mediów, do ich biernego odbioru, wzbudzając raczej zaciekawienie, niż inspirując do samodzielnych poszukiwań i kreatywnych aktywności. Nie bez znaczenia jest wspierająca obecność dorosłego: to on poka-

${ }^{24}$ I. Kalaš, Recognizing the Potential of ICT in Early Childhood Education, UNESCO Institute for Information Technologies in Education, Moscow 2010, s. 71. https:// iite.unesco.org/publications/3214673/ [dostęp: 10.08.2018]. 
zuje nowinki technologiczne dziecku, uczy ich wykorzystywania w pożądany sposób tak, aby przyczyniły się do jego rozwoju. Niewątpliwie, wszystkie aktywności online dziecka powinny być kierowane i kontrolowane przez dorosłych. Ich stała i czujna obecność wydaje się być uzasadniona i pożądana tak długo, dopóki dziecko nie będzie wykazywało się świadomością w zakresie potencjalnych, niebezpiecznych zachowań, z którymi może się spotkać online.

\section{Bibliografia}

A Common Sense Media Research Study, Zero to eight. Children's Media Use in America in 2011, 2013, https://www.commonsensemedia.org/research/zero-to-eightchildrens-media-use-in-america-2013 [dostęp: 10.08.2018].

Batorski D., Dzieci z sieci - dostęp i korzystanie z internetu przez dzieci w wieku przedszkolnym, [w:] Małe dzieci w świecie technologii informacyjno-komunikacyjnych. Pomiędzy utopijnymi szansami a przesadzonymi zagrożeniami, red. J. Pyżalski, Wydawnictwo „Eter”, Łódź 2017.

Batorski D., Technologie i media w domach i życiu Polaków, [w:] Diagnoza społeczna 2015: Warunki i jakość życia Polaków, red. J. Czapiński, T. Panek, Rada Monitoringu Społecznego, Warszawa 2015.

Dunkels E., Franberg G.M., Hallgren C., Young people and online risks [w:] Youth Culture and Net Culture: Online Social Practices, red. E. Dunkels, G-M. Franberg, C. Hallgren, I-Global 2011, http://www.mucf.se/sites/default/files/youngpeople-and-online-risk.pdf [dostęp: 11.08.2018].

Finkelhor D., Mitchell K.J., Wolak J., Online victimization: A report on the nation's youth, National Center for the Missing and Exploited Children, Alexandria 2000, http://www.unh.edu/ccrc/pdf/Victimization_Online_Survey.pdf [dostęp: 11.08.2018].

Hurlock E.B., Rozwój dziecka, Wydawnictwo Naukowe PWN, Warszawa 1985.

Juszczyk-Rygałło J., Wczesnoszkolna edukacja medialna jako wprowadzenie do edukacji całożyciowej, Prace Naukowe Akademii im. Jana Długosza w Częstochowie, Pedagogika 2015, t. XXIV, Akademia im. Jana Długosza w Częstochowie, Częstochowa 2015.

Kabali H. i in., First Exposure and Use of Mobile Media in Young Children, Pediatric Academic Societies' Annual Meeting, 25-28.04.2015, San Diego 2015, http:/ /www. abstracts2view.com/pas/view.php?nu=PAS15L1_1165.3 [dostęp: 11.08.2018].

Kalaš I., Recognizing the Potential of ICT in Early Childhood Education, UNESCO Institute for Information Technologies in Education, Moscow 2010, https:/ /iite.unesco. org/publications/3214673/ [dostęp: 10.08.2018]. 
Kemp C., Babies as young as 6 months using mobile media: Survey shows most 2-year-olds using mobile devices, with some spending more than an hour a day on screens, AAP News, https://www.aap.org/en-us/about-the-aap/aap-press-room/pages/Ba bies-as-Young-as-6-Months-Using-Mobile-Media.aspx [dostęp: 10.08.2018].

Lenhart A., Madden M., Macgill A.R., Teens and Social Media, Pew Internet $\mathcal{E}$ American Life Project, 2009, http://www.pewinternet.org/2018/05/31/teens-socialmedia-technology-2018/ [dostęp: 10.08.2018].

Livingstone S., Haddon L., EU Kids Online: Final report. LSE, London 2009, http:/ / www.lse.ac.uk/media@lse/research/EUKidsOnline/EU\%20Kids\%20I\%20(2006 -9)/EU\% 20Kids\%20Online\%20I\%20Reports/EUKidsOnlineFinalReport.pdf [dostęp: 10.08.2018].

Łobocki M., Wprowadzenie do metodologii badań pedagogicznych, Oficyna Wydawnicza „Impuls”, Kraków 2004.

Marsch M. i in., Digital Begginings: Young children's use of popular culture, media and new technology, Sheffield 2015.

Podstawa programowa ksztatcenia ogólnego dla szkoły podstawowej, http:/ / edukacjawczes noszkolna.edu.pl/wpcontent/uploads/2017/02/podstawa_programowa_2017 _sp_edukacjawczesnoszkolnaedupl.pdf [dostęp: 1.08.2018].

Papert S., Burze mózgów. Dzieci i komputery, Wydawnictwo Naukowe PWN, Warszawa 1996.

Przetacznik-Gierowska M., Makiełło-Jarża G., Psychologia rozwojowa $i$ wychowawcza wieku dziecięcego, Wydawnictwa Szkolne i Pedagogiczne, Warszawa 1992.

Pyżalski J., Od paradygmatu ryzyka do paradygmatu szans: prorozwojowe i prospołeczne używanie internetu przez dzieci i młodzież, [w:] Nastolatki wobec internetu, red. M. Tanaś, NASK, Warszawa 2016, https://akademia.nask.pl/publikacje/Na stolatki_wobec_internetu_.pdf [dostęp: 11.08.2018].

Resnick M., Computer as Paintbrush: Technology, Play, and the Creative Society, [w:] Play = Learning: How play motivates and enhances children's cognitive and socialemotional growth, red. D. Singer, R. Golikoff, K. Hirsh-Pasek, Oxford University Press 2006, http://www.computerclubhouse.org/sites/default/files/Computer AsPaintbrush_Singer.pdf, [dostęp: 10.08.2018].

Unicef, The State of the World's Children 2017: Children in a Digital World, https://www.unicef.org/publications/index_101992.html [dostęp: 9.06.2018].

Walat A., Wprowadzenie do języka i środowiska Logo, OEIiZK, Warszawa 1996.

Zevenbergen R., Logan H., Computer use by preschool children: Rethinking practices as digital natives come to preschool, Australian Journal of Early Childchood, 2008, https://research-repository.griffith.edu.au/bitstream/handle/10072/23047/53 861_1.pdf;jsessionid=5AECB87B4BB315B523C9AD98D3513C3F?sequence=1 [dostęp: 10.08.2018]. 